\title{
¿Dios en la prisión? La Trinidad, un Dios liberador y solidario
}

\author{
Jesús Martínez Gordo, \\ Facultad de Teología de Vitoria-Gasteiz
}

Tengo que confesar que me sorprendió — cuando se me propuso el título de esta aportación - su modo interrogativo: “Dios en la prisión?”. También he de decir que me hizo sonreír en un momento posterior y que, como fruto de ella, se abrió la pista de lo que podría ser mi reflexión ${ }^{1}$.

Me sorprendió, en un primer momento, porque pocas verdades son más incontestables a lo largo de la historia del cristianismo, de la teología y de la espiritualidad como la asociación de Dios con los crucificados de este mundo: Mt 25, 31 y ss.; Ex 3, 9-10; Lc 4, 18-19; Hch 12, 5; 1 Cor 12, 12-31; Heb 13, $3^{2}$.

Esta inicial sorpresa cedía el paso —en un momento posterior- a una sonrisa: el título interrogativo me hacía recordar una anécdota.

1. Intervención en el VII Congreso Trinitario Internacional Granada 2010, "Las prisiones, ¿oportunidad o fracaso? Abrid las prisiones injustas y descerrajar los cepos (Is 58, 6)", celebrado en la Facultad de Teología (campus de Cartuja), Granada, el 19 de noviembre de 2010. Agradezco a Isidro Hernández y a los Trinitarios Provincia España-Sur la publicación de esta ponencia, antes de que aparezcan las actas del Congreso.

2. Mt 25, 31 y ss.: "Lo que hicisteis a uno de estos más pequeños a mí me lo hicisteis", "estuve enfermo o en la cárcel y vinisteis a visitarme". Ex 3, 9-10: "El clamor de los israelitas ha llegado hasta mí y he visto la opresión con que los egipcios los oprimen. Ahora, pues, ve, yo te envío al faraón, para que saques a mi pueblo, los israelitas, de Egipto". Lc 4, 18-19: "El Espíritu del Señor está sobre mí, porque me ha ungido para anunciar a los pobres la Buena Nueva, me ha enviado a proclamar la liberación a los oprimidos y a proclamar el año de gracia del Señor". Hch 12, 5: "Mientras Pedro estaba en la cárcel, la Iglesia oraba por él sin cesar". 1 Cor 12, 12-31: "Del mismo modo que el cuerpo es uno, aunque tiene muchos miembros... no forman más que un solo cuerpo... así también es Cristo". Heb 13, 3: "Acordaos de los presos como si vosotros mismos estuvierais presos con ellos". 
Hace ya unos cuantos años, un "baserritarra" (hombre de campo) había resuelto casarse y, una vez hecho lo más complicado (tomar la decisión), se dirigió a la iglesia en busca del párroco. Este le acogió con una indisimulada sorpresa. No en vano nuestro buen amigo pasaba por la iglesia solo cuando ya no quedaba más remedio, y no había recibido más formación religiosa que la impartida cuando hizo la primera comunión.

El párroco le explicó amablemente los pasos que tenía que dar y cómo debía realizar, juntamente con su pareja, el preceptivo examen de lo que en aquellos años se denominaba "doctrina". Nuestro buen baserritarra, nervioso por tener que afrontar de nuevo un escrutinio, le pidió a su pároco que le adelantara algunas de las preguntas en que consistía dicha reválida de idoneidad doctrinal. El párroco, pronto a facilitar una salida lo más airosa, le formuló algunas de las posibles cuestiones.

Concretamente, le indicó que la más importante y primera de todas ellas era la de saber cuántos dioses había. Nuestro sufrido alumno, ignorando la relación de semejante pregunta con su deseo de casarse, se percató en seguida de que una contestación inadecuada le ponía fuera de juego y eso de vivir juntos sin casarse era algo muy estigmatizado en aquellos tiempos. Y lo que es peor: se percató inmediatamente de que ignoraba la respuesta. Sin embargo, aun siendo consciente de que tenía tiempo para encontrar la contestación adecuada y comunicársela en un próximo encuentro, se sintió en la obligación de responder en aquel mismo momento para que quedara claro que podía tener otros posibles fallos, pero no ese tan fundamental.

Por eso, respondió como lo hace cualquier baserritarra astuto al que se le pilla en fuera de juego: preguntando a su vez. Efectivamente, se dirigió a su párroco y le dijo: “¿Qué, pues? ¿Ha habido novedades desde que hice la primera comunión?".

Aquí se acaba la anécdota y continúa la explicación sobre la sonrisa que sucede a mi inicial sorpresa: “¿Dios en la prisión?”. ¿Con interrogantes? ¿Qué pasa? Me pregunté yo también: ¿Ha habido novedades desde que Jesús se asociara a los parias y crucificados de la tierra, tan clara, como meridianamente se puede leer en el Evangelio?

El recordatorio de este "sucedido" me llevaba, en un tercer momento, a una cuestión de mayor calado: la presentación interrogativa, que en el caso de los organizadores del congreso es fruto de un legítimo interés por captar - aunque sea provocando- la atención de posibles interlocutores. ¿No se hace eco igualmente del relativismo que también alcanza a una verdad que es y ha sido una evidencia teológica, espiritual y — hasta si se me apura— dogmática a lo largo de la historia del cristianismo: que los encarcelados son una mediación preferente en la que se manifiesta el Dios unitrino? ¿Por qué hay personas y 
colectivos cristianos a los que la misma demanda les suena a provocación y demagogia, a caer en los cantos de sirena del secularismo, a disolución —más pronto que tarde- de la fe cristiana y del misterio de Dios? ¿Por qué cuando se aborda esta cuestión no faltan quienes recuerdan el riesgo de incurrir en lo que H. Urs von Balthasar denunciaba como "ateísmo cristiano”? ¿Por qué no se critica con igual contundencia el docetismo o el fideísmo al que son proclives las aproximaciones más veritativas y estéticas al misterio de Dios?

Diríase - ante preguntas de tanto calado- que un sector importante de la teología está dejando en la cuneta verdades fundamentales e incuestionables. Y lo que es más turbador: lo hace en nombre de la integridad de la fe y en fidelidad a la revelación de Dios en Jesús. Por ello, no está de más investigar los factores que inciden en este cambio de rumbo y en su consistencia.

El afrontamiento de esta cuestión contextualiza —más allá de sorpresas y sonrisas iniciales - la presente aportación en un doble y complementario acercamiento: exponiendo cómo daban razón las primeras comunidades cristianas del misterio divino (un Dios trinitario y un Hijo encarnado, crucificado y resucitado) y analizando la primacía de una presentación estético-veritativa de la revelación cristiana en la actualidad. Y hacerlo sin perder de vista que la fragilidad dogmática y veritativa de la mediación de los pobres - y, particularmente, de los presos- en determinados sectores teológicos muy cercanos al actual gobierno eclesial no ha supuesto, afortunadamente, el descuido de la inquietud pastoral por ellos. Una vez más, la vida eclesial va por delante - y es más sabia - que determinados discursos teológicos al uso.

\section{La aproximación al misterio de Dios en las primeras comunidades}

Cuando las primeras comunidades cristianas tuvieron que dar razón del misterio trinitario, lo hicieron en diálogo con tres de los colectivos más relevantes de aquellos tiempos: la religión judía (y su conciencia de ser el pueblo elegido), la cultura grecolatina (con su descubrimiento de la razón humana) y, en un momento posterior, con las interpretaciones erróneas de la revelación cristiana que empezaban a circular entre algunos colectivos creyentes.

\subsection{La verdad y la "lógica" del misterio trinitario}

Si el encuentro con la religión judía llevó a anunciar y argumentar que Jesús era el Mesías, el Salvador esperado y que Dios era un misterio de comunión entre el Padre, el Hijo y el Espíritu, el diálogo con la cultura grecolatina permitió mostrar que tanto en el Dios unitrino como en el Resucitado se reflejaba una nueva manera de argumentar: la que prefería ajustarse a la realidad de la revelación, por sorprendente y desconcertante que fuera. Semejante disposición supuso que los principios lógico-formales, tan laboriosamente alcanzados por los pensadores griegos (fundamentalmente, el de no-contradicción y el dialéctico 
o paradójico, en menor medida), fueran comprendidos como secundarios con respecto a la lógica que se visualizaba en el Dios unitrino y en Jesús de Nazaret.

Es así como irrumpe una nueva perspectiva que irá desplegando todo su potencial explicativo a lo largo de los siglos venideros y, de manera particular, en las disputas cristológicas y trinitarias de los primeros tiempos. A su luz hay que entender el principio niceno y constantinopolitano cuando, hablando de la humanidad y divinidad de Jesús, defiende la "unidad sin confusión y la distinción sin separación". Para los padres conciliares, la unidad que se entregaba en Jesucristo prevalecía sobre la separación mental y sobre los principios formales. Y a la luz de esta perspectiva hay que entender, igualmente, que el cuarto concilio lateranense sostuviera que la afirmación de la unidad trinitaria no puede realizarse al precio de la singularidad de cada persona: "in tanta similitudine, maior dissimilitudo". Por tanto, unidad de las tres personas, pero singularidad de cada una de ellas con igual contundencia y claridad.

La "lógica católica". Esta actitud respetuosa con el misterio de un Dios unitrino y con el crucificado resucitado explica el nacimiento de lo que puede ser reconocido como la "lógica católica": más atenta a respetar el equilibrio inestable entre verdades y principios, formal y aparentemente antagónicos e inconciliables (Dios y hombre, uno y trino, inmanencia y trascendencia, universalidad y singularidad, eternidad y tiempo, belleza y fealdad, gracia y compromiso, juicio y misericordia), que dispuesta a atender exclusivamente las exigencias que se derivan de los principios lógico-formales imperantes. La lógica grecolatina ayudaba a comprender determinadas parcelas de la realidad, pero no el misterio de Dios. Servía para balbucir algo de la salvación entregada en Jesús, pero era manifiestamente incapaz de dar razón de la misma respetándola en su singularidad. Para que esto último fuera posible, era preciso desplegar una nueva manera de pensar que, como es conocido, requirió su tiempo.

S. Agustín, S. Anselmo, Sto. Tomás y S. Buenaventura van a ser algunos de los autores más notables de esta manera de aproximarse al misterio de Dios indagando su verdad. Ellos son los promotores de la teología entendida y vivida fundamentalmente como "intellectus veritatis" o "fidei". Obviamente, cada uno de ellos con sus acentos y articulaciones personales, tan incuestionables como importantes para el devenir de la teología y de la misma sociedad: S. Agustín y S. Buenaventura, muy atentos y cuidadosos con la objetividad, alteridad y gratuidad del misterio divino; S. Anselmo, más preocupado por mostrar la circularidad existente entre la gracia de la salvación divina y el ansia de eternidad por parte del ser humano — a partir de la incuestionable primacía de la gracia—; y Sto. Tomás de Aquino, particularmente sensible a la connaturalidad entre el deseo redentor de la criatura y la gracia salvífica del Dios unitrino y creador. 
El debate con los herejes es una prolongación en el ámbito doméstico del diálogo reseñado entre la cultura grecolatina y el equilibrio inestable propio de la lógica católica que se va abriendo camino. La herejía es un posicionamiento que - unas veces por ignorancia, otras por desprecio y, en ocasiones, por excesiva consideración con la lógica dominante - ni articula ni mantiene el equilibrio inestable que es propio de la verdad entregada en Jesús. Las aportaciones teológicas de los padres griegos y latinos, los dogmas promulgados en diferentes concilios, el "sensus fidelium" y los posicionamientos doctrinales del obispo de Roma ayudarán a desentrañar la verdad del punto extrapolado, los datos no tenidos debidamente en cuenta, la metodología teológica y el equilibrio inestable que es preciso mantener y proclamar.

Así, pues, la referencia permanente a estos interlocutores y la entidad de las cuestiones planteadas originarán una teología ocupada en dar razón de la salvación acontecida en Jesús al modo como se revela y permitirán el asentamiento de la "lógica católica". Nacerá y se consolidará una teología particularmente atenta a resaltar la verdad del misterio de Dios a partir de su revelación en Jesús.

La "lógica católica" y el Dios encarcelado. Pues bien, es esta misma lógica de la que se hacen cargo, entre otros, S. Agustín, S. Anselmo, Sto. Tomás o S. Buenaventura, la que emerge y se visualiza en la asociación del Dios Trinitario con los encarcelados. La "lógica" que sostiene semejante visualización - entonces como hoy - era -y sigue siendo - un escándalo para muchos colectivos cristianos y una necedad o estupidez lógica para una buena parte de los pensadores actuales: por ejemplo, para los ideólogos del neoliberalismo triunfante y para la ideología teológica que generan (con M. Novak, al frente) ${ }^{3}$.

$\mathrm{Y}$, sin embargo, en tal asociación se visualiza la singularidad y novedad de la llamada "lógica católica" que se aprecia en el Dios unitrino.

Más aún: a partir de esta "lógica católica", se inicia un proceso sorprendente tanto en la comprensión como en la regulación de las relaciones económicas, políticas, culturales y religiosas.

Basta con leer a los santos padres griegos y latinos para percatarse de que - gracias a la asociación de Dios con los encarcelados y a la lógica católica que manifiesta semejante vinculación - acabarán consagrándose en el ámbito sociopolítico adquisiciones de tanto calado como la centralidad y el respeto de la persona por ser hijo de Dios, y más allá de su comportamiento; la importancia

3. Cf. M. Novak, Raíces evangélicas del capitalismo democrático, Asociación Libro Libre, 1989; El pensamiento social católico y las instituciones liberales, Asociación Libro Libre, 1992; Teología de la Liberación: ¿en verdad liberará?, Diana, 1994, México D. F.; "La ética Católica y el espíritu del capitalismo", Centro de Estudios Públicos, 1995, Santiago de Chile. 
de la comunión en la organización de la sociedad, como cumplimiento de la democracia formal; y el respeto a una verdad que está por encima de la propia libertad personal.

\subsection{El esplendor tabórico de la Trinidad}

Es cierto que paralela a esta concepción corren otras dos: una, ocupada en mostrar la belleza - tan original como seductora - del misterio divino anticipadamente manifestado en el Tabor y, otra, que erige la bondad de un Dios asociado - y hasta confundido - con los pobres como el dato capital de la salvación y de la revelación: lo que hicisteis a estos más pequeños, a mí me lo hicisteis (cf. Mt 25, 31 y ss.). Son las perspectivas que se han acercado al misterio de Dios, seducidas más por su belleza o por su bondad que por su verdad. Son, por tanto, balbuceos del misterio de Dios que están presididos, en un caso, por la irresistible fascinación que provoca la belleza de un Dios crucificado - y el canon estético que inaugura-, y, en otro, por la sorprendente atracción de un misterio divino del que también se puede hablar a partir del amor y de la misericordia.

Un nuevo canon estético. La primera de estas perspectivas tendrá un mayor desarrollo en las iglesias orientales y subrayará el esplendor de un Dios unitrino que es — como la belleza — evidente por sí mismo, a la vez que la plenitud de la vida, del mundo y de la historia. En el Crucificado Resucitado se evidencia un nuevo canon estético. Tan importante o más que escuchar a Dios será oler su presencia, degustar su comida, contemplar su hermosura, ver su rostro, tocar su cuerpo y, en general, disfrutar de sus anticipaciones en la historia, en la Iglesia, en la creación y en la intimidad del ser humano. La liberación y la solidaridad son posibles porque la salvación ya ha acontecido en Jesús. Y son posibles como agradecido reconocimiento de la gracia en la que estamos, nos movemos y existimos. La liberación y la solidaridad son, lisamente, el anverso de la salvación.

La belleza de Dios lo llena absolutamente todo, y a la luz de tanta hermosura son contemplados y acogidos los restantes misterios, es mostrada su verdad y urgida la coherencia de vida. En esto consiste la teología entendida y practicada como "intellectus pulchritudinis".

Esta sensibilidad también se encuentra en Occidente, aunque con acentos propios (en el caso de S. Agustín) y con importantes reajustes, como así se puede constatar, por ejemplo, en la teología estética que formulará S. Buenaventura a partir de la estigmatización de Francisco de Asís. De ella se hace cargo - prolongándola, por supuesto- un teólogo de tanta importancia como H. U. von Balthasar en su estética teológica y en su teodramática.

La provocación y el consuelo de un Dios encarcelado. La singularidad del nuevo canon estético y de los sentidos espirituales resaltados por esta manera de acercarse al misterio del Dios unitrino es algo que también se visualiza en 
su asociación con los encarcelados y, por extensión, con los crucificados de este mundo. En ellos se puede apreciar, por ejemplo, cómo la belleza divina está -y sigue - crucificada y cómo los sentidos a través de los cuales se accede a semejante fuente de belleza pasan - para ser espirituales - por una adecuación a la mediación en la que se manifiesta: los encarcelados, los hambrientos, los sedientos, los perseguidos y, en general, los crucificados de todos los tiempos. El nuevo canon estético inaugurado tiene poco que ver con las apetencias y los gustos al uso. Y lo mismo sucede con el disfrute y cuidado de los sentidos.

No se trata de una prolongación de lo alcanzable cuando se deja en libertad a la fantasía estética a partir de las apetencias subjetivas, sino de la seducción y provocación que se visualiza en una asociación que - por ser gratuita y con los crucificados de este mundo- no descansa en el deseo subjetivo, sino en la generosidad del amor divino objetivado en tal asociación. Y que, por ello, es fuente de libertad y humanidad. He aquí la mejor superación crítica del ateísmo antropológico de L. Feuerbach.

Así, pues, en la vinculación del Dios unitrino con los encarcelados se transparenta un nuevo canon estético y el cuidado de unos sentidos llamados a ser -si se forman debidamente- espirituales.

Los santos padres son, una vez más, particularmente sensibles a este nuevo canon estético y a esta nueva concepción de los sentidos. Al hacerlo, impulsan una espiritualidad, una praxis y un discurso, hasta ahora completamente desconocidos.

\subsection{El amor sorprendente del Dios unitrino}

La segunda de estas perspectivas paralelas - la que es más sensible a la bondad de Dios - reconoce en los crucificados de cada época la presencia de un Dios trinitario que asume - movido por amor- la condición humana. Además, lo hace en la fragilidad de un niño y en el drama del calvario. Y abre las puertas a la esperanza y al compromiso en el misterio de la resurrección. Este modo de aproximarse al misterio de Dios es muy sensible al proceso de dignificación ("divinización”) de toda persona - sobre todo, de los sufrientes, débiles y pobres—, que se plasma en una espiritualidad entendida y vivida como "intellectus amoris".

El amor como "ágape". Desde tal perspectiva, también se muestra la verdad del amor que así nos visita y se inicia al encuentro con un Dios tan sorprendente y gratuito como plenificante y seductor, como ágape y pura gratuidad. La salvación divina muestra su entraña radicalmente humana. O, si se prefiere, el compromiso liberador descansa en su principio y fundamento gratuito. Es así como el compromiso solidario y liberador elude el pelagianismo o prometeísmo que puede rondarle, disfruta de la vida y huye de pasar factura. 
También esta espiritualidad y sensibilidad teológica se plasma en una rica y apasionante literatura entre los padres griegos y latinos, y, desde ellos, a lo largo y ancho de toda la historia de la cristiandad, particularmente entre los místicos y santos de todos los tiempos.

Ireneo es quien formula con particular fuerza una de las consecuencias de esta manera de acercarse al misterio de Dios, cuando proclama que la gloria de Dios es que el hombre viva: "Gloria Dei homo vivens". En este enorme y riquísimo cauce encontramos siglos después, entre otros, a S. Juan de Mata y S. Félix de Valois, dos santos particularmente sensibles a la gratuita presencia de Dios en los encarcelados y, por extensión, en los crucificados de todos los tiempos.

El escándalo de un Dios encarcelado por amor. Y llegados a este punto, brota, una vez más, la pregunta: ¿se puede sostener que Dios está en la prisión cuando nos aproximamos al misterio de la Trinidad de esta manera? La respuesta no se hace esperar: sin duda de ninguna clase. Y está por pura gratuidad. Por tanto, no porque los recluidos, los hambrientos, los sedientos y harapientos de este mundo sean necesariamente buenos, sino porque el Dios unitrino es bueno. Es la gratuidad de la asociación de Dios con los presos lo que cura a este modo de acercarse, vivir y hablar del misterio de Dios de su riesgo pelagiano y prometeico: estamos gratuitamente con los encarcelados porque Dios se ha vinculado gratuitamente con ellos y con nosotros.

Además, esta manera de acercarse al misterio de Dios posibilita la adquisición de verdades - teóricas y prácticas - de tanta envergadura, como la propiedad universal de la tierra; la distinción entre gestionar y apropiarse de los bienes; la diferenciación entre pobreza y pobres; la hipoteca social de toda propiedad; la preferencia de Dios por los pobres no porque sean necesariamente buenos, sino como expresión de su bondad, es decir, porque Dios es bueno; la discriminación positiva; la condena de la usura o la relación entre ayuno, ayuda y limosna. En ella encuentran sus raíces la política fiscal redistributiva de nuestros días y, en general, el reparto de la riqueza. A ella también hay que recurrir para saber cómo han dialogado los grandes hombres y mujeres de la tradición cristiana - teólogos y santos, en su gran mayoría - cuando han confrontado el misterio de la salvación divina con los poderes económicos y políticos de todos los tiempos.

Es asombroso que esta perspectiva - capital en la revelación del proyecto salvífico de Dios y omnipresente en la tradición cristiana - no haya tenido -ni tenga todavía - un puesto medianamente relevante en la dogmática cristiana. En el mejor de los casos, quedaba recluida en el área de lo que se entendía como disciplinas prácticas o en el apartado de la espiritualidad. La historia de la teología muestra que son escasas las ocasiones en las que ha salido de semejante reclusión y ha ocupado la centralidad que también le corresponde no solo académicamente, sino también como principio estructurador del seguimiento de Jesús. 


\section{Trinidad y encarcelados en la teología actual}

La consecuencia de estas opciones es que el cristianismo que actualmente se favorece $-\mathrm{y}$ el que tiene una excelente recepción mediática- es el propuesto desde la perspectiva veritativa. Lo que preocupa $-\mathrm{y}$ sigue interesando a importantes sectores de eclesiales y mediáticos- es la verdad del misterio de Dios y, en menor medida, el encuentro - síntesis de caricia y aguijón a la vez-con el misterio de Dios y su misión liberadora y fraterna.

\subsection{Trinidad y diálogo interreligioso}

Así, por ejemplo, el interlocutor judío de los primeros tiempos no solo ha llevado a una espectacular reconsideración de la incuestionable importancia del pueblo de Israel en la historia de la salvación (conviene recordar que es el pueblo y la cultura de Jesús, de María y de los Apóstoles), sino que ha desembocado - de la mano del Concilio Vaticano II y, particularmente, de Juan Pablo II- en una sorprendente autocrítica y en una admirable petición de perdón por la cuota de responsabilidad que ha correspondido a la Iglesia en el nacimiento, consolidación y extensión del antisemitismo en suelo formalmente cristiano ${ }^{4}$.

Se ha descubierto, igualmente, la importancia decisiva de la Shoah o exterminio nazi no solo en la creación del Estado judío actual y para la teología hebrea (un acontecimiento - al decir de algunos- de tanto alcance revelador como la entrega de las tablas de la Ley en Sinaí), sino también para el cristianismo y la humanidad de todos los tiempos. Los millones de judíos exterminados y el modo como se ha procedido a ello han puesto de manifiesto el lado oscuro de la condición humana, han sometido a crisis radical el proyecto ilustrado - obligando a revisar a fondo todas sus pretensiones- y nos han hecho más cautos ante las posibilidades humanizadoras del progreso.

Y desde el punto de vista teológico, nos ha llevado a percibir con una fuerza inusitada no solo la indudable e incuestionable tragedia personal de cada judío masacrado, sino también el drama histórico de la cruz que se actualiza en cada encarcelado, más allá de las divergencias teóricas o de las cosmovisiones legítimamente diferenciadas entre las religiones.

Ampliación de interlocutores. Pero hay más. Esta primera interlocución con la religión judía, autocríticamente reconsiderada después del Vaticano II, ha posibilitado la apertura al diálogo - cierto que con muchas tensiones y conflictos $\mathrm{y}$, a veces, inevitables encontronazos - con otras religiones en las que - entonces como hoy - se encuentran "logoi spermatikoi" (semillas de salvación): primero,

4. J. Martínez Gordo, "La centralidad de la shoah en el diálogo judeo-cristiano", Scriptorium Victoriense, vol. 51, n. ${ }^{\circ} 1-4$ (2004), pp. 55-141. 
con el islam; después, con el animismo africano; más recientemente, con el budismo y el hinduismo.

La ampliación de interlocutores es, como se puede apreciar, tan enorme como interesante, a pesar de que en la reconsideración de la salvación que dichos diálogos abren no falten los excesos sincretistas, los complejos relativistas y las decisiones erróneas. Entre estas últimas, conviene recordar la precipitada prohibición de los ritos chinos y malabares. Una desafortunada medida que ha mermado las posibilidades de implantación del catolicismo en el continente asiático, tan inmenso como poblado.

Por su parte, la prolongación del diálogo con otras confesiones cristianas ha servido para plantear algunos puntos calientes en el ámbito estrictamente doméstico, y que siguen abiertos actualmente: el modo como se ha de entender el primado de Pedro (de honor o de jurisdicción, centralizado o patriarcal y policéntrico), la relación entre Escritura y tradición, el carácter constitutivo o funcional del ministerio ordenado, la existencia de la salvación en la Iglesia católica y fuera de ella, o la "subsistencia" de la iglesia universal en las iglesias locales.

Son cuestiones, muchas veces de metodología teológica, en las que se ventilan verdades fundamentales y en cuya resolución se ha tenido que pagar el precio de escisiones y herejías. En todas ellas se sigue jugando el ecumenismo contemporáneo.

Del dia-logo a la dia-praxis. Y, sin embargo, es compartido por todas las religiones y confesiones - más allá de las posibles divergencias identitarias y riesgos reseñados - el cuidado de lo que se reconoce como el diálogo de la vida y de la praxis, y, por ello, el fecundo encuentro interreligioso y ecuménico que brota a partir de la atención a los dolientes de este mundo, empezando, por supuesto, con los encarcelados.

He aquí un punto de encuentro interreligioso y ecuménico, una dia-praxis, difícilmente cuestionable y perfectamente constatable. En realidad, es volver a recordar - de la mano de Sto. Tomás de Aquino- que todo diálogo es un discurso de segundo grado, ya que brota y se sostiene en el discurso primero que es el encuentro con Dios en la oración y en los crucificados de este mundo y, de entre ellos, en los encarcelados.

\subsection{Trinidad y pensamiento moderno}

También el diálogo de las primeras comunidades cristianas con la cultura grecolatina ha experimentado una ampliación de interlocutores y de cuestiones a lo largo de los siglos.

Forma parte de nuestro saber teológico reconocer que a los primeros tiempos de la cristiandad - en los que se subrayó la gracia y la objetividad del misterio de 
Dios - sucedió un momento posterior presidido por la reivindicación de la subjetividad y de la libertad frente a cualquier verdad y ante toda autoridad que no fuera la de la razón humana moviéndose en libertad. Son las señas de identidad de la modernidad.

Igualmente forma parte de la cultura europea reconocer en dicho movimiento ilustrado tres corrientes perfectamente diferenciadas, aunque no igualmente tenidas en cuenta: la idealista, la empirista y la romántica. Más conocidas y estudiadas las dos primeras y más relegada la tercera.

Y forma parte de nuestro común saber la posterior evolución de la modernidad hacia posicionamientos idealistas, materialistas, neopositivistas, existencialistas y postmodernos. Queda más en la penumbra - no exenta de cierto desconcierto - la entidad del nihilismo contemporáneo y su alcance teológico.

Pocos discuten que, como consecuencia de este permanente diálogo con la modernidad, el misterio de Dios unitrino tiene que vérselas, más tarde o más temprano, con los proyectos salvíficos que aletean en tales movimientos: el deísmo, el panteísmo, el kantismo o modernismo, el tradicionalismo o fideísmo, el materialismo, el neopositivismo, el ateísmo y hasta el antiteísmo.

Más perplejidad provoca en nuestros días la relación que se ha de mantener con el agnosticismo, ya que, si bien es cierto que se ha convertido en el concepto talismán en el que se refugia una buena parte de la herencia increyente, también lo es que se asiste al nacimiento de posicionamientos muy cercanos a una actitud exigible a los cristianos cuando se aproximan al misterio del Dios unitrino.

La finitud es absoluta, aproblemática y satisfecha. Probablemente, sea E. Tierno Galván quien haya formulado con particular claridad - bajo el ropaje de una posición formalmente agnóstica- lo que es el corazón del ateísmo y del antiteísmo más beligerante de nuestros días, cuando sostenía que la finitud era absoluta, aproblemática y satisfecha.

Se trata - entonces como hoy- de una caracterización que desaloja - porque no necesita- cualquier clase de salvación que esté más allá o más acá del esfuerzo humano. La nada - y no el misterio de Dios o su ágape- es el principio y el final. En el intermedio queda una vida, una historia y la realidad absoluta, aproblemática y satisfecha de cada día, es decir, un paraíso - cuando no un infierno - entre una "nada" inicial que volverá a aparecer al final de la existencia humana.

La finitud como agonía, maravilla y ética. Pero junto a este agnosticismo - exultante por la emancipación alcanzada, y claramente ateo y antiteístacoexiste otro que centra su atención en la nada, en el vacío y en el silencio en que queda sumida la condición humana, una vez que Dios ha sido desalojado de la finitud. Y en la relación que el ser finito mantiene con dichas "nada", "vacío" 
y "silencio". Es así como enmudece la alegría primera del ateo y del antiteísta y entra en escena el realismo trágico que se expresa por medio de aquellos agnósticos o ateos para quienes la razón ilustrada se ha autoimpuesto un límite que no puede transgredir (el de la finitud). Sin embargo, semejante autocensura no puede evitar una relación ineludible con la ausencia, el silencio y la oscuridad que está más allá de lo finito. Es una relación que puede ser descrita en términos de angustia o lucha (para traer dicho silencio, nada o ausencia al concepto), maravilla (porque, a pesar de todas las negaciones, la "nada", el "silencio" y el "vacío" están presentes en nuestra existencia) y de ética (porque hay que cuidar una relación tan singular, superando los intentos de reprimirla o acallarla).

Este agnosticismo evidencia que cuando se piensa en toda su radicalidad, la absolutez de la finitud y su tesis nihilista, se acaba superando - más tarde o más temprano- la tendencia ilustrada a ignorar, despreciar o condenar como irrelevante aquello que está más allá de lo atrapable conceptualmente. Y, lo que es más sorprendente, se acaba reconociendo que la razón finita mantiene - a pesar de todas las negaciones precedentes - un singular trato con eso que, estando más allá de lo finito, se sigue manifestando y percibiendo como "ausencia", como "nada" o como "silencio". En la experiencia de la finitud se da una presencia de dichas "ausencia", "nada" y "silencio", aunque sea como agonía, maravilla y ética.

La cercanía de esta clase de agnosticismo con la experiencia cristiana del Viernes Santo es indudable. Por lo menos, ayuda a mostrar el otro lado, angustioso y trágico de la finitud, del que la frivolidad en que frecuentemente incurre una supuesta "liberación" atea o antiteísta no se ha percatado o no ha tenido en la debida cuenta. Y, sobre todo, actualiza y pone en valor la veta agnóstica del cristianismo a la que tan sensibles fueron, entre otros, el Pseudo Dionisio, Nicolás de Cusa y la gran mayoría de los místicos. Es cierto que se puede hablar de Dios y de su proyecto salvífico porque el Dios trinitario ha tenido a bien revelarse y revelarlo, pero es igualmente cierto que sigue siendo un misterio y que debe ser tratado como tal. Es una importante llamada de atención que tiene poco que ver con la proclividad docetista a la que se exponen quienes apuestan -y más, si es unilateralmente- por la perspectiva veritativa en su acercamiento al misterio de Dios.

Así, pues, el diálogo con algunas corrientes agnósticas contemporáneas está ayudando a recuperar la dimensión mistérica de la salvación cristiana: en la ausencia y en el silencio de algunos agnósticos nihilistas contemporáneos, reaparece la vieja y desconcertante constatación de que el misterio es primero experimentado, aunque sea como agonía, y luego es balbucido.

La razón compasiva. Y, sobre todo, que esta actualización existencial de una especie de Viernes Santo especulativo muestra la importancia de no absolutizar 
la razón positivista o formal, ya que, además de sentiente, es también $-\mathrm{y}$ sobre todo- compasiva y misericordiosa. Una razón de este calado nos permite percibir y llevar al concepto no solo los admirables y conmovedores Viernes Santos especulativos reseñados, sino, sobre todo, los Viernes Santos que se actualizan por doquier en los rostros y tragedias personales de la inmensa mayoría de los crucificados de este mundo, empezando por los encarcelados.

Solo una razón compasiva y misericordiosa podrá experimentar lo que es el corazón de la revelación cristiana cuando articula verdad y amor: que quien ama conoce a Dios y está en Dios ( $c f .1 \mathrm{Jn} 4,8)$. Y que lo está más allá de que sus aportaciones teóricas sean fallidas o brillantes. El misterio de la resurrección -y su cimiento en el amor divino- ilumina las actualizaciones de los Viernes Santos y se constituye en el principio y fundamento de la razón compasiva y misericordiosa.

\subsection{Esplendor y eclipse de la Trinidad como amor}

Por otra parte, la aproximación al misterio de Dios desde la perspectiva del amor va a desplegar un enorme potencial espiritual, veritativo y práctico a lo largo de la toda la historia de la cristiandad, para acabar eclipsada en el siglo XIX y primera mitad del XX.

Mientras el cristianismo es vivido como amor gratuito y entendido como "intellectus amoris", se asiste, por ejemplo, a la formulación de Pierre de Blois (1135-1203): el pobre es el vicario de Cristo ("pauper Christi vicarius est”), algo que hoy suena desmedidamente atrevido a muchos oídos. Y, sin embargo, a la luz de la espiritualidad y de la teología que recoge esta expresión hay que entender acontecimientos históricos de tanta entidad, como la institución y eclipse del diaconado; el franciscanismo y la crisis de los "fratricelli"; la admirable y sorprendente redención de cautivos y encarcelados; el debate sobre los derechos de los indios en la conquista de América, a partir de su reconocimiento como hijos de Dios; la apuesta por la educación de las clases obreras y más pobres, el nacimiento de los llamados socialistas religiosos y el eclipse de la perspectiva amorosa, con el subsiguiente nacimiento del marxismo en los siglos XIX y XX.

Parece llegada la hora de reconocer la parte de responsabilidad que en tal olvido tienen no solo los escarceos de algunos teólogos (pocos, por cierto) con la ideología marxista (no así con sus diagnósticos sociales), sino también, y sobre todo, los gravísimos problemas del galicanismo y del conciliarismo para la unidad de la Iglesia; la frustración generada por la pérdida de los Estados pontificios; la búsqueda compulsiva de una autoridad magisterial y moral en el Concilio Vaticano I, más cercana al absolutismo monárquico que a la comunión trinitaria, y el consecuente repliegue (hasta el encapsulamiento) de la curia vaticana sobre sí misma a lo largo de los siglos XIX y buena parte del XX. 
La urgencia de estas preocupaciones ayuda a entender - aunque no justifica, por supuesto- el debilitamiento de la centralidad de los pobres en la vida y en la teología católica, el fuerte subrayado del asistencialismo, la actual tolerancia con el docetismo y, por paradójico que pueda resultar, la irrupción de la misma ideología marxista.

A nadie se le escapa la gravedad de tal descuido ni las nefastas consecuencias que ha tenido. Una presencia más consistente de esta aproximación desde el amor al misterio de Dios hubiera servido, al menos, para denunciar semejante carencia y anunciar los costos previsibles de la misma.

La centralidad que, a pesar de todo, sigue teniendo la modernidad veritativa y emancipadora, con todas sus modulaciones posteriores, no puede desconocer que a las reivindicaciones de la primera de las revoluciones modernas (en el fondo, razón y libertad sin fraternidad) ha sucedido en el inicio del siglo XX una segunda revolución (la de la solidaridad sin libertad).

La caída del Muro de Berlín (1989) no solo ha servido para mostrar el rostro violento de la solidaridad sin libertad o el fracaso ideológico del marxismo, sino también las trágicas consecuencias que ha tenido, incluso para la humanidad, el eclipse de la teología entendida como "intellectus amoris", durante una buena parte del siglo XIX.

\section{Los crucificados en una Trinidad estético-veritativa}

Esta actualización de interlocutores y temas, con el consecuente primado de la perspectiva veritativa, es, como se puede apreciar, apasionante. Pero también insuficiente.

Lo es, en primer lugar, porque no mantiene —como así sucedía en los primeros tiempos- el equilibrio deseable con las otras dos maneras de acercarse al misterio de Dios revelado en Jesús: desde la belleza y desde la bondad.

Y lo es, en segundo lugar, porque cuando se atiende únicamente a la perspectiva veritativa se acaba ofreciendo un discurso acartonado, escasamente seductor y esterilizante. La historia de la escolástica y de la neoescolástica es el mejor y más elocuente ejemplo. El riesgo de incurrir en docetismo es difícilmente refutable, por más que sea en nuestros días el error con el que se es más tolerante.

Actualmente, son pocos los que cuestionan que el acceso al misterio de Dios desde un interés exclusivamente veritativo tiene un corto recorrido si no recupera la capacidad de seducción que es propia de lo bello.

\subsection{La teología estética de H. U. von Balthasar}

Sobran acertadas denuncias en esta dirección. Quizá la más conocida sea la de H. U. von Balthasar, cuando estableció aquella diferenciación, ya clásica, entre la teología académica o de laboratorio y la teología hecha de rodillas. 
No tiene nada de extraño que más recientemente los partidarios de primar la dimensión veritativa del misterio de Dios estén intentando articularse con la belleza. En el origen de tal inquietud se encuentra no solo la reseñada denuncia de H. Urs von Balthasar o la incuestionable esterilidad de la escolástica, sino también un legítimo interés por resaltar la objetividad de la verdad con la intención de denunciar y superar la herencia subjetivista y antropocéntrica traída por la Ilustración. La belleza es evidente y seduce por sí misma. Gracias a ella es posible mostrar la alteridad y objetividad de una verdad que también tendría que seducir y fascinar por sí misma.

Es, como se puede apreciar, una apelación desde intereses — una vez más manifiestamente veritativos. No tiene nada de extraño que en esta clase de teología el amor acabe tratado como el hermano menor, a pesar de estar llamado a ser el polo articulador de la verdad y de la belleza.

Sin embargo, esta aproximación estético-veritativa al misterio del Dios unitrino presenta un problema de fondo ya en el mismo H. Urs von Balthasar, el más reciente inspirador de la misma: su ahistoricidad y, por ello, su tendencia a entender que la única estética verdaderamente relevante es la que se desarrolla en el seno de la Trinidad amorosa entre el silencio del Padre que envía, la palabra del Hijo obediente en la cruz y el encuentro de palabra y silencio que coexisten en el Espíritu Santo. Por eso, dedicará miles de páginas a esta teodramática y casi ninguna — por no decir ninguna - a la tragedia de quienes actualizan en nuestro mundo y en nuestro tiempo el drama del Dios trinitario: los crucificados de este mundo, empezando por los encarcelados.

La teología "simbólica" de B. Forte y las encíclicas de Benedicto XVI (Deus caritas est y Caritas in veritate) son dos ejemplos en los que se puede comprobar esta crítica constatación.

\subsection{La "simbólica eclesial" de B. Forte}

Casi nadie discute la implantación estético-veritativa de la teología de Bruno Forte. A él se deben algunas sugerentes aportaciones sobre el modo como se revela el misterio de Dios y una seductora manera de hacer teología. Son muchos los que han quedado fascinados por su manera de hablar de la verdad revelada y por la forma, estéticamente cuidada, de su aportación.

Probablemente, serán muy pocos los que conozcan que este gran teólogo ha escrito las páginas más importantes de su "simbólica eclesial" viviendo en el corazón del barrio que controla la camorra napolitana y que lo ha hecho padeciendo algunas veces sus secuelas: robo, intento de extorsión, amenazas, intimidaciones, etc. Su entereza moral ante la versión partenopea de la mafia es algo que está fuera de toda duda, a pesar de que sea más desconocida que su aportación teológica. 
$\mathrm{Y}$, sin embargo, siendo esto admirable e incuestionable, es sorprendente que en toda su obra teológica no haya dedicado ni siquiera una línea a este drama que angustia a Nápoles y afecta a toda Italia. Su "simbólica eclesial", ocupada en dialogar con el pensamiento contemporáneo más actual, descuida el dramático espesor de la vida cotidiana que le rodea, sin dejar de adoptar valientes y admirables posicionamientos personales al respecto.

Este fue el punto central del debate que mantuvimos en el congreso internacional celebrado en 1996, al publicarse el último volumen de su "simbólica eclesial" en la Pontificia Facultad Teológica de la Italia Meridional5. Allí se pudo comprobar que ese era el precio que tenía que pagar un teólogo ocupado en dialogar con la primera de las modernidades y sus epígonos contemporáneos (reivindicación de la libertad y de la razón frente a la autoridad y la revelación del misterio de Dios), pero que acababa descuidando en su perspectiva teológica (no así en su vida personal y pastoral) la segunda de las revoluciones (la fraternidad sin libertad) y el triunfo actual del neoliberalismo, con sus secuelas fundamentalistas en lo económico y en lo político.

\subsection{Deus caritas est y Caritas in veritate (Benedicto XVI)}

La encíclica Deus caritas est (2005) fue recibida con un sinfín de parabienes. Y la verdad es que había motivos para ello, sobre todo si se tenían presentes los diagnósticos sobre el postconcilio y la gestión del papa J. Ratzinger al frente del dicasterio para la doctrina de la fe.

Se percibía en la encíclica un tono más propositivo, para nada polémico y, mucho menos, condenatorio. Además, abordaba la buena noticia del amor, algo que el cristianismo ha considerado desde siempre el corazón mismo de la salvación cristiana. Benedicto XVI dejaba de lado otras posibles consideraciones más sociológicas y discutibles, y anunciaba, proponía, argumentaba y trataba de convencer.La estructura del documento presentaba dos grandes apartados: un primero, ocupado en mostrar la teología del amor, y un segundo, en el que concluía algunas interesantes y oportunas orientaciones pastorales. Es cierto que gustó mucho la perspectiva marcadamente antropológica de la parte sistemática de la encíclica y sus diálogos con diferentes corrientes filosóficas, particularmente con las que remaban en contra de la concepción cristiana del amor o con las que podían ser asumidas como apoyatura desde la que mostrar la singularidad del amor cristino.

5. Cf. J. Martínez Gordo, "Simbólica teológica y compromiso por la justicia. La teología fundamental de Bruno Forte", Lumen, vol. 46 (1997), pp. 3-36. Cf., también, "L'armonia della rivelazione in un tempo disarmonico", en AA. VV., Una teología come storia. La 'simbolica ecclesiale' di Bruno Forte tra filosofia e teologia, Milano, 1998, pp. 237-253. 
Pero es igualmente cierto que sorprendió la irrelevancia teológica de los pocos diagnósticos políticos y económicos que aparecen en la encíclica. La confrontación sin paliativos que mantiene con el marxismo desde su estancia como profesor en Münster y Tubinga le volvía a jugar una mala pasada y le dificultaba dialogar con las ciencias sociales, es decir, con aquellos saberes en los que también $-\mathrm{y}$, a veces, preferentemente- se actualiza el amor de Dios y se juega la bondad de los católicos en nuestros días.

Benedicto XVI parece tener dificultades para reconocer que el marxismo es una corriente que pertenece más al pasado que al presente, aunque todavía se pueden dejar sentir, cierto que con escasa potencia, algunas de sus consecuencias ideológicas más indeseadas. Las legítimas prevenciones que manifiesta tener ante el marxismo no solo parecen dificultarle la apertura a una cierta autocrítica eclesial (que también ayuda a explicar su relativo éxito), sino que tienen un peso desmedido en su dificultad para percibir el fundamentalismo económico que atenaza y destroza a las dos terceras partes de la humanidad, y la ideología neoliberal que lo justifica ${ }^{6}$.

La publicación del primer tomo de su cristología no ha hecho sino confirmar estas primeras impresiones; algo explicable a partir del riesgo que presenta la apuesta por una perspectiva veritativa (y, a veces, pretendidamente estética), sin la debida articulación con la bondad.

La posterior publicación de la encíclica Caritas in veritate en 2009 ha confirmado estas consideraciones valorativas sobre la perspectiva veritativa que sigue primando el papa J. Ratzinger.

\subsection{Amor y dogmática neoliberal}

Estos tres ejemplos ilustran cómo en nuestros días, a diferencia de los primeros tiempos de la Iglesia, somos muy conscientes de que lo que mueve al mundo y en lo que se juega su suerte no es tanto en el diálogo interreligioso (por más que haya interés en denunciar, legítimamente, por cierto, el fundamentalismo religioso que azota algunas áreas del globo), ni tampoco en el debate intelectual y de escuela (por impactante y hasta interpelante que pueda ser el caso de los nihilistas trágicos contemporáneos con su mística increyente), ni tampoco en los debates más domésticos (el caso de Mons. Lefebvre, la problemática recepción del Vaticano II durante el pontificado de Juan Pablo II, la novedad relativa de un papa teólogo, las observaciones — poco consistentes, por cierto- sobre la

6. Cf. J. Ratzinger, Fe, verdad y tolerancia. El cristianismo y las religiones del mundo, Salamanca, 2005. Esta observación vale para sus análisis económicos (particularmente, de la economía neoliberal triunfante), no así para sus diagnósticos de la democracia formal burguesa. 
cristología de Jon Sobrino o de J. A. Pagola, etc.), sino en los saberes económicos y políticos que canalizan o no la bondad.

Y que lo hacen con sus incuestionables aciertos, pero también con sus fundamentalismos enmascarados y, sobre todo, con sus víctimas bien visibles. Los encarcelados, entre estos últimos.

No son las cuestiones sobre el sentido las que mueven al mundo, sino aquellas en las que se juega la posibilidad de un destino fraterno, por más que algunos laicismos de corto vuelo puedan y deban preocupar, al menos coyunturalmente. El peso de la dogmática neoliberal triunfante es tal que muchos de los debates veritativos pueden parecer irrelevantes ante el drama de la muerte antes de tiempo de las dos terceras partes de la humanidad, y ante el dolor y el sufrimiento de los enfermos, sedientos, hambrientos, desnudos y encarcelados.

La asignatura pendiente de muchas comunidades cristianas es el crítico diálogo entre la dogmática neoliberal imperante y la verdad - tan descolocante como provocadora- de un Dios que muestra la fuerza de su amor en el fracaso histórico de la cruz y en los crucificados de este mundo, empezando por los encarcelados.

\section{Conclusión: ¡Dios en la prisión!}

¿Está Dios en la prisión? Igual, no queda más remedio que adoptar la estrategia del baserritarra de la anécdota inicial y responder preguntando, pero en esta ocasión no por ignorancia: ¿es que ha cambiado el Evangelio y la voluntad de Jesús de estar preferentemente asociado a los crucificados de este mundo no porque sean buenos, sino porque Él es bueno? ¿Es que acaso no es -cuando menos - tan legítima la manera de acercarse al misterio de Dios desde la bondad que desde la belleza o desde la verdad? Más aún, si es correcto que la fe y la esperanza pasarán pero no el amor, ¿no habría que reivindicar la centralidad de la bondad sobre la verdad y la belleza en la vida cristiana y en el discurso teológico?

¡Enhorabuena si el título propuesto por los organizadores pretendía provocar esta u otra reflexión por el estilo! Objetivo alcanzado.

Solo queda que cada uno de nosotros cambiemos las interrogaciones por dos admiraciones tan firmes como irremplazable es la asociación del Dios trinitario con los crucificados de este mundo y, de modo particular, con los encarcelados: ¡Dios en la prisión!

A nosotros nos resta verle, cogerle de la mano, olerle, tocarle e iniciarnos —en el canon estético tan sorprendente como original- que inaugura el Dios unitrino. Y, a la vez, percibir operante en dicha presencia una verdad que - ayer como hoy - sigue siendo escándalo para muchos de casa - particularmente, para los sensibles a lo estético-veritativo sin encarnadura histórica- y necedad para los biempensantes, los postmodernos, los neoliberales y los indiferentes. Para nosotros: fuente inagotable y siempre novedosa de verdad, bondad y belleza. 